\title{
Sedentary Time and Disability in Older Adults: A Systematic Review and Meta-Analysis
}

\author{
Luria Melo de Lima Scher ${ }^{1,2,3^{*}}$, Flávio Renato Barros da Guarda ${ }^{2,4}$, Mauro Virgílio Gomes de Barros ${ }^{2}$, Zhiguo \\ Chen ${ }^{1}$, Stephen D. Anton ${ }^{1,5}$
}

${ }^{1}$ Department of Aging and Geriatric Research, University of Florida, FL, USA; ${ }^{2}$ Research Group in Lifestyle and Health, University of Pernambuco, PE, Brazil; ${ }^{3}$ Departmant of Physical Education, University of State of Bahia, BA, Brazil; ${ }^{4}$ Department of Public Health, Federal University of Pernambuco, PE, Brazil; ${ }^{5}$ Department of Clinical and Health Psychology, University of Florida, FL, USA

\begin{abstract}
This systematic review and meta-analysis examined the relationship between sedentary behavior (SB) and disability in older adults. A search was conducted using PubMed, Web of Science, and Sport Discus databases to identify eligible studies. Of the 405 studies identified, only 4 studies met our predefined criteria to be included in this metaanalysis. In these studies, participants who reported having a disability had higher levels of SB (effect size: 0.38, 95\% IC: $0.14-0.62, p<0.002)$ than those without disability. Older adults with disabilities seem to engage in higher levels of SB (mean 5.8 to 10.3 hours/day) when compared with older adults without disability (mean of 4.6 to 9.7 hours/ day). The findings of this review and meta-analysis suggest that there is an association between SB and disability. Our findings, however, are limited to cross-sectional studies and thus direction of this relationship is not clear based on studies to date.
\end{abstract}

Keywords: Activities of daily living; Sedentary behavior; Aging; Lifestyle

\section{INTRODUCTION}

In the United States the prevalence of disability in older adults is increasing [1-3] and the Centers for Disease Control and Prevention (CDC) highlight that 2 in 5 older adults have a disability [4]. Disability limits the functional autonomy and can be defined as a difficulty in performing activities of daily living and instrumental activities of daily living, or mobility limitation [5,6]. In older adults different types of disability have been studied, such as difficulties with activities of daily of living (ADL), difficulties with instrumental activities of daily (IADL) and mobility disability $[1,7,8]$.

Overall, studies have shown that individuals aged 75 and older are most affected by all types of disability and are more likely to be female, frail, minority, and have a chronic conditions $[4,7,9,10]$. A recent paper by Díaz-Venegas et al [11] also highlights that older adults who have any of the three most common types of disabilities (ADL, IADL and mobility disability) have an increased risk of all cause mortality. Recently increased attention has focused on the potential role of sedentary behavior (SB) in contributing to the development of disability in older adults [12]. This concern is mainly focused on older adults who spend more time in $\mathrm{SB}$ compared to other age groups [13]. SB, which is defined as excessive involvement in activities that require low energy expenditure $(\leq$ 1.5 METs), typically performed in the sitting position, has been associated with reduced functional capacity and disability in older adults [12-18].

A growing body of evidence also indicates time spent in SB can increase the risk for many chronic disease conditions, as well as development of a disability $[4,19]$. Specifically, studies have shown that while adults and children spend on average 7.7 hours/day in sedentary behavior, older adults spend even more time in SB (sitting or reclining), with an average of 8.0 to 11 hours per day $[13,20]$. This amount of time spent in SB, in older adults, may predict functional disability and also contribute to an increase in the burden of multiple chronic diseases resulting in the elevation of healthcare costs and increased risks for mortality [3,14,21-23]. Both television viewing and the total time in SB are significantly associated with disability in older adults [24,25].

Recent studies have reported that, independent of engagement in

"Correspondence to: Dr. Luria Melo de Lima Scher, Department of Aging and Geriatric Research,University of State of Bahia, University of Pernambuco, University of Florida, Gainesville, FL, USA, Tel: +55-79988418156, E-mail: luriamelo@gmail.com

Received: June 18, 2019, Accepted: June 30, 2019, Published: July 07, 2019

Citation: Scher LML,Guarda FRB, Barros MVG, Chen Z, Anton SD (2019) Sedentary Time and Disability in Older Adults: A Systematic Review and Meta-Analysis. J Aging Sci 7: 206.doi:10.35248/2329-8847.19.07.206

Copyright: (C) 2019 Scher LML, et al. This is an open-access article distributed under the terms of the Creative Commons Attribution License, which permits unrestricted use, distribution, and reproduction in any medium, provided the original author and source are credited. 
physical activity (PA), SB represents an important risk factor for functional limitations and disability in older adults [21,25,26]. Although SB is considered a modifiable risk factor for disability among the geriatric population [25], there are few longitudinal studies investigating the association of SB with functional disability in older adults [12]. Moreover, it is important that future studies analyze the relationship between both total SB, and different types of SB (e.g.TV viewing) [25] in older adults with and without functional disability [24].

A better understanding of how sedentary behavior affects older adults with and without disability is important to improve their quality of life, as well as to reduce the burden of adverse health outcomes and healthcare costs. Thus, the aim of this systematic review and meta-analysis was to estimate the relationship between sedentary behavior and functional disability (such as ADL, IADL or limitations to mobility) in longitudinal, observational studies, as well as examine whether older adults with functional disability engage in higher levels of sedentary behavior than those without functional disability.

\section{METHODS}

\section{Search strategy and study selection}

A search was conducted in PubMed, Sport Discus, and Web of Science from January 2018 to April 2018. Observational studies (cohort, longitudinal and cross-sectional) were included. The articles published in the period from January 2000 to April 2018 were searched, using the following combination of keywords terms and Medical Subject Headings: (1) "older adults," OR "elderly," OR “aged," OR “ageing," OR "65 years and older;” (2) AND "disability," OR "activities of daily living," OR "ADL disability," OR "ADL," OR "limitation of activity" (3) AND "Sedentary lifestyle," OR “inactivity," OR sitting," "television," OR "sitting time," OR "sedentary time;" (4) AND "cohort," OR "longitudinal” OR "cross-sectional" OR "studies." We used these terms/descriptors combined with the operators OR (i.e., between the terms) and operator AND was used to create a relationship between keywords set and each Boolean operator available in these databases as well as the filters for excluding animal research, reviews, guidelines, theses, and dissertations. The construction of the research question was based on the acronym PICO that represents Patient, Intervention, Comparison and Outcome.

This systematic review and meta-analysis followed PRISMA statement guidelines [27]. The decision to include articles in this review was conducted in two stages; in the first stage, the title and abstract were evaluated for topic relevance. Once the relevance was clear, the full text was read to determine final inclusion or exclusion. In the second stage, any disagreement about inclusion was referred to a third reviewer and resolved by discussion. The process of screening and selecting papers was conducted by two reviewers (L.M.L S and F.R.B.G) working independently and a third author (S.D.A) was asked in case of disagreement.

\section{Eligibility criteria}

The selected articles were limited to studies which included older adults ( $>60$ years), reported sedentary time (sum of screen time, reading, naps, and other sedentary behaviors), and included a measure of disability based on ADL or IADL, or mobility disability, and/or mobility following [7] recommendations, and were written in English. More specifically, we included studies that measured sedentary behavior in the following ways: i) used the measure of total sedentary behavior through sitting, reclining and lying downtime; ii) measured the physical activity (PA) instruments by direct (pedometers, accelerometers, frequency meters) or indirect (questionnaires) methods.

Only published studies from 2000 to April 2018 were included and we also searched the reference lists of selected papers. The studies were excluded for the following reasons:

1) Studies in which the term sedentary was used synonymously with the statement absence of PA practice (or insufficient physical activity practice).

2) Studies with subpopulations having specific illnesses or are in nursing homes.

3) Studies with different statistical measures and tests that do not permit comparison with other selected papers or only present one group with disability, that is, without other comparison group without disability and finally, studies that considered breaks in sitting time (ST) as variable or measure with and time balance of active leisure and sedentary time (TBLAST).

\section{Data extraction}

The extracted data included study design, baseline study year, age, baseline sample, final sample size, follow up time, population characteristics, characteristics of measured disability. In addition, it was also included domain of disability studied, sedentary behavior measure, type of behavior measure, mean of age, mean of sex, mean and SB standard deviation for each group, type of risk reported with $95 \%$ CIs of the association between sedentary behavior and disability and how the odds ratio was calculated. When the information was not available in the papers, a request was sent to authors about the information and data.

\section{Statistical analysis}

The studies selected were pooled to calculate the effect size by computing standardized mean difference (SMD) in minutes per day with Hedges' g, between the disability group SB and no disability group sedentary time, in accordance with the measured disability (ADL, IADL, or limitations to mobility). The effect size of each study is the standardized mean difference in sedentary time for disability group minus no disability group sedentary time. Heterogeneity of effects across studies was estimated by $\mathrm{I}^{2}$ statistics, which is a measure of the variation that is caused by heterogeneity between studies, and is larger when heterogeneity increases [28].

The random effects model was used to estimate the overall effect size and to compare the weighted average sedentary time between the group with functional disability and the group without a functional disability [29]. Z-Statistics were used to derive the P value of the test for the overall random effect. All statistical analyses were performed in R 3.3.2 [30]. Each P-value was based on a two-sided alternative hypothesis, and a level of 0.05 or below was considered statistically significant. A meta-regression was used to explore the relationship of effect size with age and sex.

The checklist of STROBE (Strengthening the Reporting of 
Observational Studies in Epidemiology) criteria [31] was used to evaluate the quality of eligible studies. Each criterion of STROBE received a score from 0 to 1 , and two reviewers independently evaluated all criteria and gave a grade from 0 to 22 to each article. Lastly, the final grade calculated with an average was transformed into percentage to better evaluate the quality of the articles. When these articles reached a percentage greater than 50\%, they were classified as good quality.

\section{RESULTS}

Figure 1 shows the study selection process. A total of 405 articles were identified by database search, and 1 additional record was identified through the reference lists of included studies. After removing duplicates, these papers were lowered to 304 with relevant titles and abstracts, but 183 articles were excluded after reading title and abstract. Of the 121 records screened, 32 articles were considered eligible for inclusion in this review. After reading the full-text analysis, 28 articles did not meet the inclusion criteria. The most frequent reasons for exclusion were: articles with breaks in sedentary time (i.e., with interruptions to SB) $(n=2)$ and time balance of active leisure and sedentary time (TBLAST) $(n=1)$, articles that had statistical measures that did not allow for comparison between the studies selected to the meta-analyses $(n=5)$ and one article had only one group with disability $(n=1)$. In total, 4 studies were qualitatively synthesized and appraise in the metaanalysis.

Table 1 presents characteristics of the four selected studies. Two studies were carried out in the United States [21,32], one in Portugal [33] and one in Taiwan [34]. Furthermore, a majority of these studies were conducted between 2014 and 2017, and the sample size varied from 140 to 2,286. In these studies, with reference to the age for inclusion, two studies included individuals aged $\geq 60$ years and two included aged $\geq 65$ years. All the articles included both sexes, and the type of ethnicity was considered for analyses in three articles whereas one article did not mention the ethnicity. Moreover, three articles presented the baseline year [3,21,34] and one article did not show baseline year [33].

Three of the four articles included in this review reported the assessment of total sedentary time in minutes per day [3,33,34], the other reported SB in hours/day [21]. Three studies evaluated SB objectively using accelerometer devices identified by activity $<100 \backslash$ counts per minute (cpm) [21,32,33], while one study evaluated the association between ST and mobility limitation using only one question [34]. In contrast, the physical disability in the studies selected was measured indirectly ( 3 self-reports and 1 questionnaire), which was based on the information provided by individuals. The ADL and IADL measurement scales were the most commonly used instruments. Only two studies focused on evaluating low extremity mobility [3,34].

All studies selected were adjusted for multiple potential confounding variables including age and gender [3,21,34] which allowed us to explore in our analysis the relationship of effect size with age and sex. Overall, all studies also included the assessment
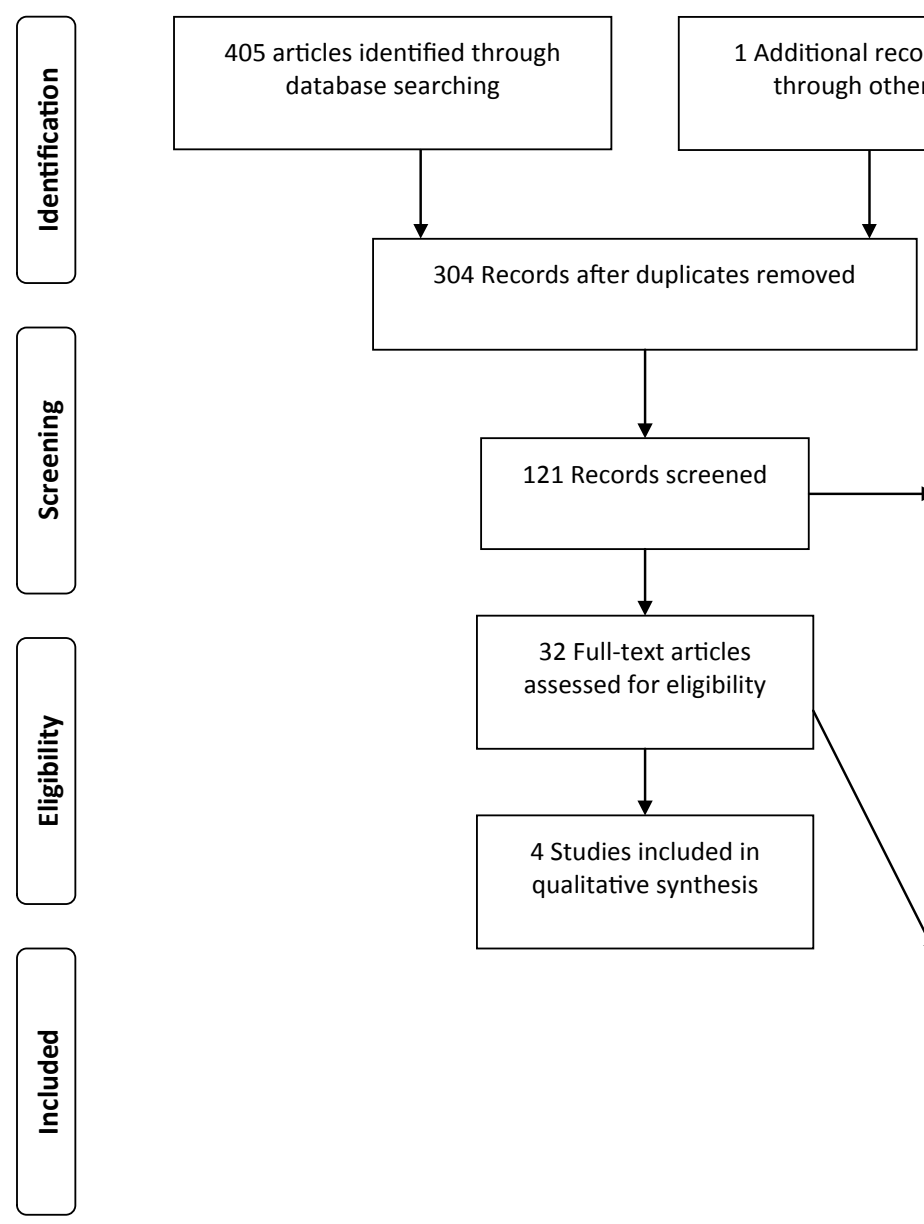

183 Records excluded

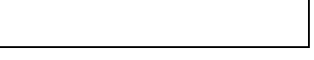

28 Full-text articles excluded. 19 did not met inclusion Criteria

9 disability combined with different variables. 3 Disability or long-term health 3 Age less than 60 years 2 Function decline no disability 1 Immobility and not sedentary behavior 1 with different measure of SB

9 studies were included in inclusion criteria, but excluded due:

2 with breaks and $1 T_{\text {BLAST }}$ 5 statistical measure not allow comparison

1 with only one group with disability

Figure 1: Flow Diagram of Study. 
Table 1: Characteristics of studies included in meta-analysis.

\begin{tabular}{|c|c|c|c|c|c|c|c|}
\hline Study & $\begin{array}{c}\text { Baseline } \\
\text { age }\end{array}$ & Sample size & Baseline Year & Sex & $\begin{array}{c}\text { Population } \\
\text { characteristics }\end{array}$ & Domain of disability studied & Sedentary Behavior Measure \\
\hline $\begin{array}{l}\text { Dunlop et } \\
\text { al. } 2015\end{array}$ & $\geq 60$ & $\begin{array}{c}2,910 \\
\text { (baseline), } \\
\text { 2,286 (Final } \\
\text { sample) }\end{array}$ & $2005-2006$ & $\begin{array}{l}\text { Female } \\
\text { and } \\
\text { Male }\end{array}$ & $\begin{array}{l}\text { The National Health } \\
\text { and Examination } \\
\text { Surveys,nationally } \\
\text { representative } \\
\text { samples of the non- } \\
\text { institutionalized U.S. } \\
\text { population. }\end{array}$ & $\begin{array}{l}\text { ADL : Self-reported ADL } \\
\text { limitations, Questions: "By } \\
\text { yourself and without using any } \\
\text { special equipment, how much } \\
\text { difficulty do you have [with the } \\
\text { particular task]"? "Self-care tasks: } \\
\text { getting in and out of bed, eating, } \\
\text { dressing, or walking". }\end{array}$ & $\begin{array}{l}\text { Objective measure: } \\
\text { Accelerometer (uni-axial); } \\
\text { average daily ST (hours) and } \\
\text { the daily percentage of time } \\
\text { registering as sedentary during } \\
\text { wear hour. }\end{array}$ \\
\hline $\begin{array}{l}\text { Manns et al. } \\
2015\end{array}$ & $\geq 60$ & $\begin{array}{c}2,730 \\
\text { (baseline) } \\
\text { 2,017(Final } \\
\text { sample) }\end{array}$ & $\begin{array}{c}2003 \text { to } 2004 \\
\text { and } 2005 \text { to } \\
2006 .\end{array}$ & $\begin{array}{l}\text { Female } \\
\text { and } \\
\text { Male }\end{array}$ & $\begin{array}{l}\text { The National Health } \\
\text { and Nutrition } \\
\text { Examination Survey, } \\
\text { representative sample } \\
\text { of the U.S. }\end{array}$ & $\begin{array}{l}\text { Physical function Domain of } \\
\text { lower extremity mobility Self- } \\
\text { reported Evaluated issues: "lower } \\
\text { extremity mobility, general } \\
\text { physical activity, ADLs, IADLs } \\
\text { and functional limitation". In } \\
\text { addition, two questions about } \\
\text { "ability to walk one-quarter of a } \\
\text { mile and to walk up } 10 \text { steps". }\end{array}$ & $\begin{array}{c}\text { Objective measure: } \\
\text { Accelerometery Time in } \\
\text { sedentary }(<100 / \text { counts per } \\
\text { minute (cpm). ST, min/d Breaks } \\
\text { in sedentary time, total times } \\
\text { per day. }\end{array}$ \\
\hline $\begin{array}{l}\text { Marques et } \\
\text { al. } 2014\end{array}$ & $\begin{array}{l}\text { aged } \\
65-103 \\
\text { years }\end{array}$ & 371 & Not avaible & $\begin{array}{l}\text { Female } \\
\text { and } \\
\text { Male }\end{array}$ & $\begin{array}{l}\text { Caucasian } \\
\text { community- } \\
\text { residing Portuguese } \\
\text { population aged } 65 \\
\text { and up. }\end{array}$ & $\begin{array}{l}\text { Mobility disability status : Ability } \\
\text { to "walk } 800 \text { m," to "climb } \\
\text { stairs to the second floor," and } \\
\text { to "perform heavy housework." } \\
\text { Questionnaire"Are you able to: } \\
\text { "walk } 800 \text { m," to "climb stairs } \\
\text { to the second floor," and to } \\
\text { "perform heavy housework." }\end{array}$ & $\begin{array}{l}\text { Objective measure : } \\
\text { Accelerometry. The cutoff values } \\
\text { used to define the intensity } \\
\text { was }<100 \text { counts per minute, } \\
\text { including activities that involve } \\
\text { energy expenditure at the level of } \\
\text { 1.0-1.5 METs. ST min/day. }\end{array}$ \\
\hline $\begin{array}{c}\text { Ye, Ku, } \\
\text { Wang, } 2017\end{array}$ & $\geq 65$ & 140 & $\begin{array}{c}\text { January } 2010 \\
\text { to December } \\
2012\end{array}$ & $\begin{array}{l}\text { Female } \\
\text { and } \\
\text { Male }\end{array}$ & $\begin{array}{l}\text { Independent Man } \\
\text { and women }(>65) \\
\text { from } 8 \text { community } \\
\text { centers in Taichung, } \\
\text { Taiwan }\end{array}$ & $\begin{array}{l}\text { Mobility disability status Ability } \\
\text { to "walk } 800 \text { m," to "climb } \\
\text { stairs to the second floor," and } \\
\text { to "perform heavy housework." } \\
\text { Questionnaire"Are you able to: } \\
\text { "walk } 800 \text { m," to "climb stairs } \\
\text { to the second floor," and to } \\
\text { "perform heavy housework." }\end{array}$ & $\begin{array}{l}\text { Objective measure : Time spent } \\
\text { sitting (min/day). Question: } \\
\text { "During the last } 7 \text { days, how } \\
\text { many hours do you estimate you } \\
\text { spend sitting?" and a prompts } \\
\text { with } 6 \text { questions to help elderly } \\
\text { to remember what did they do in } \\
\text { each } 24 \text { hours in the last } 7 \text { days. }\end{array}$ \\
\hline
\end{tabular}

of chronic conditions and body mass index, as covariates. In addition, only two studies reported adjusting the statistical analyses for interactions with PA $[21,33]$. The majority $(n=3)$ presented a type of risk reported as odds ratio with $95 \%$ confidence limits. For example, it was showed that independent of the level of PA, the ADL disability was associated with every hour increased in SB $(\mathrm{OR}=1.52,95 \% \mathrm{CI}: 1.10,2.10)$ [21]. In contrast, one study, had a correlation between losing physical independence and sitting time (ST), but ST was not a significant predictor of losing physical independence in a regression model analyses to interaction with age, gender [33]. However, these analyses, also, showed combined effects of moderate PA combined with age and sex as predictors of the risk of losing physical independence in older adults.

Table 2 shows the scores for the evaluation of the methodological quality of the studies selected for this this meta-analysis. These scores ranged from 18.5 to 20.9 with a mean percentage agreement of $90.05 \%$ between the reviewers. Two studies involved a crosssectional sample of the population [21,32], a study involved a representative cross-sectional [33] and one used a convenience sample [34]. The study quality was evaluated based on the classification in 3 categories, following the proposal of [35]: A when the study met more than $80 \%$ of the criteria established in STROBE; B - when $50 \%-80 \%$ of the STROBE criteria were met; and $\mathrm{C}$ - when less than $50 \%$ of the criteria were fulfilled.

Figure 2 shows the results of meta-analysis, with the type of comparison, the weights of these studies and the pooled of mean difference from studies reporting that there was a positive relationship between disability and the increasing of the mean of $\mathrm{SB}$ in the group with disability, compared with the group without disability [(effect size: 0.38 (95\% IC: 0.14-0.62)] p=0.002]. In addition, overall heterogeneity was high and significant when the studies were pooled ( $\mathrm{p}<0.001 ; \mathrm{I}^{2}=83 \%$ ). The exclusion of one study [32] during sensitivity analyses decreased heterogeneity from $83 \%$ to $15 \%(\mathrm{p}=0.30)$, however, it wasn't significant and increased the overall effect size from 0.38 to 0.48 . The meta-regression result showed that both age and sex effects were not significant $(p=0.308$ and 0.136$)$ respectively.

Table 3 lists the reasons studies were excluded from this review. Major reasons for which studies were excluded were the following: (i) disability or SB combined with different variables, such as cognitive ability [36], sleep-wake disturbances [37] mortality [22,38], falls [39] or (ii) the combination of disability with a longterm health, for example, people that reported needing assistance with tasks due of long-term illness or disability were included with a major disability[40-42]. Of these 12 studies, 6 were cohorts and 6 cross-sectional, and only one study [39] did not include both sexes. Few studies $(n=2)$ used disability objective measures $[37,43]$ when compared with the use of the SB objective measures $(n=4)$ $[36,37,44,45]$. Some studies were excluded, in this meta-analysis, 
Table 2 : Assessment quality of studies according to STROBE criteria.

Score and percentage of quality of the articles from STROBE criteria (Strengthening the Reporting of Observational Studies in Epidemiology).

\section{Reference}

Dunlop et al. 2015

Manns et al. 2015

Marques et al. 2014

Yen, Ku, Wang, 2017

\section{kind of study}

Cross-sectional of population-based

Cross-sectional of population- based

Cross-sectional representative

Cross-sectional

\section{Scores}

20.3

20.9

19.5

18.5
$\%$

$92.40 \%$

$95 \%$

$88.60 \%$

\begin{tabular}{|c|c|c|c|c|c|c|c|c|}
\hline \multirow[b]{2}{*}{ Study } & \multicolumn{3}{|c|}{ Disability } & \multicolumn{2}{|c|}{ No Disability } & \multirow[b]{2}{*}{ Total } & \multirow[b]{2}{*}{ Weight } & \multirow{2}{*}{$\begin{array}{l}\text { Std. Mean Difference } \\
\text { IV, Random, 95\% Cl }\end{array}$} \\
\hline & Mean & SD & Total & Mean & SD & & & \\
\hline Dunlap et al 2015 & 590.4 & 78.0 & 103 & 530.4 & 105.6 & 2183 & $26.2 \%$ & $0.57[0.38 ; 0.77]$ \\
\hline Manns ot al 2015 & 595.1 & 229.1 & 547 & 550.8 & 336.5 & 1470 & $30.1 \%$ & $0.14[0.04 ; 0.24]$ \\
\hline Marques et al 2014 & 621.9 & 114.7 & 95 & 583.0 & 114.4 & 276 & $24.5 \%$ & $0.34[0.10 ; 0.57]$ \\
\hline Yen, Ku, and Wang 2017 & 348.7 & 129.7 & 88 & 281.8 & 110.0 & 52 & $19.2 \%$ & $0.54[0.19 ; 0.89]$ \\
\hline Total $(95 \% \mathrm{Cl})$ & & & 833 & & & 3981 & $100.0 \%$ & $0.38[0.14 ; 0.62]$ \\
\hline \multicolumn{9}{|c|}{ Heterogeneity: a $^{2}=0.049 ; \mathrm{Chi}^{2}=18.07, d \mathrm{~d}=3|\mathrm{P}<0.001 \mathrm{x}|^{2}=83 \%$} \\
\hline
\end{tabular}

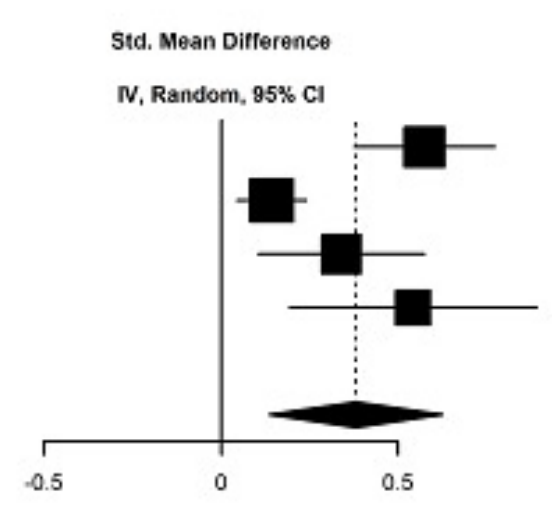

Figure 2: Random effect model for the effect size of each study and the pooled of mean difference from studies reporting that there was a positive relationship between disability and sedentary behavior in the group with disability compared with the group without the disability.

Table 3 : Characteristics of studies excluded.

Studies excluded due disability or sedentary behaviour combined with different variables

Cross-sectional studies

\begin{tabular}{|c|c|c|c|c|c|c|c|}
\hline \\
\hline Study & $\begin{array}{l}\text { Baseline } \\
\text { age }\end{array}$ & Sample size & $\begin{array}{l}\text { Baseline } \\
\text { Year }\end{array}$ & Sex & Population characteristics & Domain of disability studied & $\begin{array}{c}\text { Sedentary Behavior } \\
\text { Measeure }\end{array}$ \\
\hline $\begin{array}{l}\text { Vancampfort, } \\
\text { et al., } 2018\end{array}$ & $\begin{array}{r}18-49 \\
50-64 \\
\geq 65\end{array}$ & 42,469 & $2007-2010$ & $\begin{array}{l}\text { Male and } \\
\text { Female }\end{array}$ & $\begin{array}{l}\text { World Health } \\
\text { Organization's Study on } \\
\text { Global Ageing and Adult } \\
\text { Health. Conducted in } \\
\text { China, Ghana, India, } \\
\text { Mexico, Russia, and } \\
\text { South Africa. }\end{array}$ & $\begin{array}{l}\text { Disability ADL, Ability to } \\
\text { washing whole body, getting } \\
\text { dressed, moving around } \\
\text { inside home, eating, getting } \\
\text { up from lying down, and } \\
\text { using the toilet. }\end{array}$ & $\begin{array}{l}\text { One question } \\
\text { about: SB (sitting or } \\
\text { reclining/ min/day) }\end{array}$ \\
\hline $\begin{array}{l}\text { Fragoso et al., } \\
2014\end{array}$ & $\begin{array}{l}70-89 \\
\text { years }\end{array}$ & 1,635 & 2010 & $\begin{array}{l}\text { Male and } \\
\text { Female }\end{array}$ & $\begin{array}{l}\text { Elderly from centers the } \\
\text { LIFE Study with low } \\
\text { physical activity and lower } \\
\text { extremity functional } \\
\text { limitations }\end{array}$ & $\begin{array}{l}\text { Mobility Limitation: } \\
\text { Objective measure } 400-\text {-meter } \\
\text { walk test }(400 \mathrm{MWT}) \text { and } \\
\text { SPPB test }\end{array}$ & $\begin{array}{c}\text { Objective measure } \\
\text { Accelerometry - } \\
\text { ActiGraph GT3X } \\
\text { and ActiLife software. } \\
\text { Sedentary time = } \\
<100 \text { counts } / \text { minute }\end{array}$ \\
\hline $\begin{array}{l}\text { Kim, Im, Choi, } \\
2017\end{array}$ & $\begin{array}{c}\text { Age } \\
\text { group } \\
20-39 ; \\
40-59 ; \\
60-79 \\
\text { (n: } 608) ; \\
\geq 80 \\
\text { (n:401) }\end{array}$ & $\begin{array}{l}5,359(\text { total }) \geq 60 \\
+\geq 80=\text { n: } 1,009\end{array}$ & 2003 & $\begin{array}{l}\text { Male and } \\
\text { Female }\end{array}$ & $\begin{array}{l}\text { Adults from the National } \\
\text { Health and Nutrition } \\
\text { Examination Survey 2003- } \\
\text { 2006. United States }\end{array}$ & $\begin{array}{l}\text { Survey about activity } \\
\text { limitation as a Health- } \\
\text { related Quality of } \\
\text { Lifecomponent."usual } \\
\text { activities, such as self-care, } \\
\text { work, or recreation" on the } \\
\text { last } 30 \text { days }\end{array}$ & $\begin{array}{c}\text { Objective measure } \\
\text { Accelerometery } \\
\text { records (< } 100 \text { counts/ } \\
\text { min })\end{array}$ \\
\hline $\begin{array}{c}\text { Coqueiro et al., } \\
2017\end{array}$ & $\geq 60$ & 316 & 2011 & $\begin{array}{l}\text { Male and } \\
\text { Female }\end{array}$ & $\begin{array}{l}\text { Older adults enrolled } \\
\text { in the Family Health } \\
\text { Strategy who live in the } \\
\text { urban area of Brazil }\end{array}$ & $\begin{array}{l}\text { Frailty Components: } \\
\text { shrinking, weakness, } \\
\text { poor endurance/ } \\
\text { exhaustion,slowness and low } \\
\text { activity. }\end{array}$ & $\begin{array}{l}\text { SB was determined } \\
\text { from the fifth and } \\
\text { last domains of IPAQ; } \\
\text { Time (hours/day) } \\
\text { that the older adults } \\
\text { remains seated in } \\
\text { different places. }\end{array}$ \\
\hline
\end{tabular}

Cohort studies-Studies excluded due disability or sedentary behavior combined with different variables 


\begin{tabular}{|c|c|c|c|c|c|}
\hline $\begin{array}{l}\text { Martínez- } \\
\text { Gómez et al } \\
2014\end{array}$ & $\geq 60$ & $\begin{array}{c}\text { Total: } 7,243 \\
4008 \text { (in 2001) - } \\
3235 \text { (in 2003) }\end{array}$ & 2001-2003 & $\begin{array}{l}\text { Male and } \\
\text { Female }\end{array}$ & $\begin{array}{l}\text { Representative } \\
\text { population of the non- } \\
\text { institutionalized Spanish } \\
\text { population of elderly }\end{array}$ \\
\hline
\end{tabular}

León-Muñoz et al 2013

2635 (base
line) and Final
Sample Size: 1789
(because 846
died) $\quad \begin{gathered}2001 \text { and } \\ 2003\end{gathered} \quad \begin{gathered}\text { Male and } \\ \text { Female }\end{gathered}$

Prospective cohort of persons representative of the Spanish population.
Mobility and agility.Mobility limitation, questions about: "difficulty in picking up or carrying a shopping bag";

"difficulty in climbing one flight of stairs"; and city blocks".

Self rerported about: Mobility limitation Questions about: "difficulty in picking up or carrying a shopping bag";

"climbing one flight of stairs"; "walking several city blocks; and agility limitation". "difficulty in walking several

SB questions: "About how much time do you spend sitting down on weekdays?" This question also was asked with reference to a weekend day.

Number of sitting hours, question: "About how much time do you spend sitting down on weekdays? Please add up the total number of hours that you spend sitting down regardless of the activity that you do (eating, listening to the radio, watching television, reading, sewing, driving, etc.)". (Continues on next page)

Cohort studies- Studies excluded due disability or sedentary behavior combined with different variables

\begin{tabular}{|c|c|c|c|c|c|}
\hline $\begin{array}{c}\text { Wen Ku et al } \\
2017\end{array}$ & $\begin{array}{l}\text { Aged } 65 \\
\text { or older }\end{array}$ & $\begin{array}{c}285 \text { (base line) } \\
\text { and Final Sample } \\
\text { Size: 274) }\end{array}$ & $2012-2014$ & $\begin{array}{c}\text { Male and } \\
\text { Female }\end{array}$ & $\begin{array}{l}\text { Community-dwelling } \\
\text { older adults across } 14 \\
\text { regions in Taiwan }\end{array}$ \\
\hline $\begin{array}{l}\text { Jefferis et al } \\
2015\end{array}$ & $60-79$ & $\begin{array}{c}\text { base line: } 3137 \\
\mathrm{n}: 1655 \text { (returned } \\
\text { the } \\
\text { accelerometer). } \\
\text { Final size: } 1455\end{array}$ & $2010-2012$ & Male & $\begin{array}{c}\text { The British Regional } \\
\text { Heart Study, prospective } \\
\text { cohort. }\end{array}$ \\
\hline $\begin{array}{l}\text { Guallar- } \\
\text { Castillón et al } \\
2007\end{array}$ & $\geq 60$ & $\begin{array}{l}\text { In 2001,n:4008 } \\
\text { (base line) (In } \\
\text { 2003, n:3235; } \\
\text { Final size: } \mathrm{n}: 3235\end{array}$ & $2001-2003$ & $\begin{array}{l}\text { Male and } \\
\text { Female }\end{array}$ & $\begin{array}{c}\text { Representative of the non } \\
\text { institutionalized Spanish } \\
\text { population ages } 60 \text { years } \\
\text { and older. }\end{array}$ \\
\hline
\end{tabular}

Cross-sectional studies - Studies excluded due the use of disability or long-term health

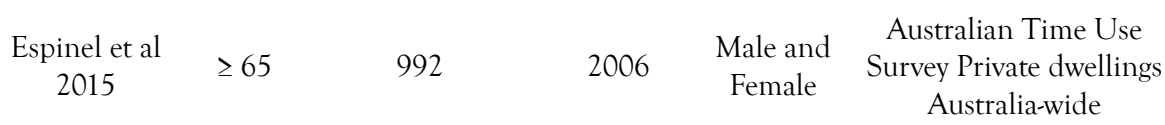

Questionare about: "Disability or long-term health condition (yes or no)"

Functional capacity "the Medical Outcomes Score Physical Functioning". It was considered to have a major

\begin{tabular}{|c|c|c|c|c|}
\hline $\begin{array}{l}\text { Banks et al } \\
2010\end{array}$ & $\begin{array}{c}45 \mathrm{yr} \\
\text { and } \\
\text { above }\end{array}$ & 91,266 & 2006 & $\begin{array}{c}\text { Male and Man and Women of New } \\
\text { Female }\end{array}$ \\
\hline
\end{tabular}

disability the participants that reported needing assistance with daily tasks due of longterm illness or disability.

Cohort studies-Studies - excluded due the use of disability or long-term health

\begin{tabular}{|c|c|c|c|c|c|}
\hline $\begin{array}{l}\text { Vander Ploeg } \\
\text { et al } 2014 .\end{array}$ & $\begin{array}{l}45 \mathrm{yr} \\
\text { and } \\
\text { older }\end{array}$ & 221,240 & $2006-2012$ & $\begin{array}{l}\text { Male and } \\
\text { Female }\end{array}$ & $\begin{array}{c}\text { Australia population from } \\
\text { the state of New South } \\
\text { Wales (NSW) }\end{array}$ \\
\hline
\end{tabular}

Self-reporting- "Help with daily tasks because of long term illness or disability. No or yes".
Objective measure

Triaxial accelerometry (GT3X+, ActiGraph, Pensacola, FL, USA)

Objective measure GT3 x Accelerometer (ActiGraph, Pensacola, FL)

SB Question: "I do no exercise but remain seated for the major part of my leisure time (reading, going to the cinema, watching television, etc)".

No measure (sedentary activity measured by the Compendium of $\mathrm{PA})$

Question about Sitting time: "How many hours in each $24 \mathrm{~h}$ day do you usually spend doing the following: watching television or using a computer; sitting; sleeping";

Self-reporting "About how many hours in each $24 \mathrm{~h}$ day do you usually spend sitting?" 
because they used statistical methods that did not allow comparison with the studies included in the meta-analysis.

Although these excluded studies did not allow comparison with the other studies selected, they showed that SB was significantly associated with an increased dependence on others for activities of daily living, mobility limitations (defined as any difficulty walking $500 \mathrm{~m}$ ) and objective physical function measures (using 400-m walk time) $[20,46,47]$. In addition, Van Cauwenberg et al [48] did not examine total $\mathrm{SB}$, but the relationships of time spent watching TV with individual, social and physical environmental correlates and found high levels of television viewing in older adults with functional limitations. Moreover, in these studies, three used SB subjective measures $[20,46,48]$ and one used an objective measure of SB [47].

\section{DISCUSSION}

This systematic review and meta-analysis examined the relationship between SB and physical disability in older adults, and analyzed if older adults with disability based on ADL or IADL, or mobility disability were likely to have higher levels of sedentary behavior (SB). This is the first meta-analysis examining the relationship between total SB in hours per day and physical disability in older adults without specific chronic conditions. There were a few important findings. First, there are few published observational studies that have examined the association of SB and disability in older adults. Moreover, most available findings were published in the last four years, using cross-sectional designs and were conducted with much methodological variability regarding the operationalization of physical disability measures. Second, the key finding was that there is a significant relationship between functional disability and time spent in SB in older adults. Moreover, older adults with a disability spend a mean of 5.8 to 10.3 hours/day of their waking time being sedentary compared to older adults without disability who spend a mean of 4.6 to 9.7 hours/day in SB. These findings suggest that older adults with a disability spend more time in SB than older adults without disability, which may predispose them to even more negative consequences.

Chen et al [49] in a cross-sectional study showed that shorter ST and breaks in ST were associated with lower risk of IADL disability independent of moderate-to-vigorous physical activity (MVPA). In a recent review with older adults, however, it was reported that crosssectional studies did not allow a causal relationship to be found due to the reverse causality [50]. This suggests a bi-directional relationship whereby impaired mobility could lead to an increase in $\mathrm{SB}$, which makes it difficult to understand the relationship between $\mathrm{SB}$ and risk of physical function decline in this population. Gardiner et al [51] in a recent study investigated the associations of ST with changes in physical function, and physical function with changes in ST, in adults aged $\geq 45$ years and these researchers reported be bidirectional the relationship between functional limitations (FL) and ST. To investigate the bidirectional associations between ST and physical function the researchers conducted two analyses. In the first analyses, it was investigated whether ST at baseline was associated with functional decline during the follow-up. In the second analyses, they investigated whether physical functional observed at baseline was changed during the follow-up when the exposure to sedentary time was changed. In addition, this study showed significant associations between functional limitations and
ST for all group analyzed. For example, high levels of SB were a predictor of decline in physical function, but only in women and in those older adults with severe functional limitations, in this study the decline in physical function, also was predicted of high levels of $\mathrm{SB}$ in older adults [51].

The majority of the included studies in this meta-analysis had good methodological quality with sufficient sample size. Our review, however, was limited to four observational studies with different technical methodological standardizations, and such proceedings may have contributed to high heterogeneity as well had compromised the selection process of participants different [29]. In addition, the effects SB has on older adults can be quite variable and factors such as physical activity level as well as age, gender, and the presence of chronic conditions may influence the pattern of SB. For example, Marques et al [33] reported the different patterns of SB between older adults with low and moderate functioning (i.e. low functioning group presented a high risk of losing physical independence compared with the moderate functioning group).

Our study has some limitations, for example: the majority of studies included in this review used self-reported measures of SB that might underestimate the prevalence of disability [52]. The number of studies using objective measures to assess disability has increased, however, self-report tools are a reliable mostly is used instruments in epidemiological studies [53]. Second, the predominance of cross-sectional studies makes it impossible to establish a causal association and the evidence suggests a likely bi-directional relationship between $\mathrm{SB}$ and disability. Third, this meta-analysis had only 4 studies that could explain the wide heterogeneity. Fourth, grey literature was not included in this meta-analysis such as theses, dissertations, government reports, conference papers, among others.

Longitudinal studies are necessary to estimate the magnitude of the relation between ST and the risk of physical disability in geriatric populations. In addition, disability measures in these studies need to be standardized. There is a limited amount of evidence on the association of SB and disability that analyzes the interactions with different levels of PA [21,32]. Besides, it is important that future studies examine quantity of $\mathrm{SB}$, not only specific context but also the total sedentary time, and examine the influence of sex and age when analyzing these interactions with chronic conditions and different levels of PA. Quantifying the dose of ST in older adults with and without a disability using statistical measures that may be compared with other studies is also an important factor.

Based on the studies seen in the literature, the method of measurement of physical disability should ideally be standardized across studies. In addition, it is necessary to stratify older adults into more homogeneous subgroups. Indeed, Marques et al [33] noted that older adults with different levels of functional capacity had different patterns of SB, for example older adults with moderate functioning were younger, physically active and spent less time in SB. However, in this study after the regression analysis, SB did not predict the risk of losing physical independence. Another interesting point that should be noted is that low functional capacity may contribute to SB and also be a consequence of SB [25].

\section{CONCLUSION}

This meta-analysis summarized the findings of previous observational studies and suggests that there is an association 
between physical disability and total ST in older adults. Overall, older adults with a disability spend a mean between 5.8 to 10.3 hours/day in sedentary activities, so it is necessary and appropriate that the geriatric population be encouraged to spend less time in sedentary behavior, mainly between those with some functional disability. The population should be encouraged to spend less time on sedentary behavior, especially among adults more exposed to sedentary behavior. In addition, longitudinal studies are necessary to estimate the magnitude of the relation between ST and the risk of physical disability in older adults using objective measures of disability and SB.

\section{REFERENCES}

1. Seeman TE, Merkin SS, Crimmins EM, Karlamangla AS. Disability trends among older Americans: National Health and Nutrition Examination surveys, 1988-1994 and 1999-2004. Am J Public Health. 2010;100(1):100-107.

2. Lin SF, Beck AN, Finch BK, Hummer RA, Master RK. Trends in US older adult disability: Exploring age, period, and cohort effects. Am J Public Health. 2012;102(11):2157-2163.

3. Manns P, Ezeugwu V, Armijo-Olivo S, VallanceJ, Healy GN. Accelerometerderived pattern of sedentary and physical activity time in persons with mobility disability: National Health and Nutrition Examination Survey 2003 to 2006. J Am Geriatr Soc. 2015;63(7):1314-1323.

4. CDC (2018) Disability and Health.

5. Bruin, A Nossikov, A Picavet HS. Health interview surveys Towards international harmonization of methods and instruments. WHO regional publications. European series. 1996;58: 1-161.

6. Yang M, Ding X, Dong B. The Measurement of Disability in the Elderly: A systematic review of self-reported questionnaires. J Am Med Dir Assoc. 2014;15(2):150.e1-150.e9.

7. Wong E, Backholer K, Gearon E, Harding J, Freak-Poli R, Stevenson $\mathrm{C}$, et al. Diabetes and risk of physical disability in adults: A systematic review and meta-analysis. The Lancet 2013;1(2):106-114.

8. Pahor M, Guralnik JM, Ambrosius WT, Blair S, Bonds DE, Church TS, et al. Effect of structured physical activity on prevention of major mobility disability in older adults: The LIFE study randomized clinical trial. JAMA. 2014;311(23):2387-2396.

9. Gill TM, Kurland B. The burden and patterns of disability in activities of daily living among community-living older persons. The Journals of Gerontology Series A: Biological Sciences and Medical Sciences. J Gerontol A Biol Sci Med Sci. 2003;58(1):70-75.

10. Vander Vorst A, Zijlstra GA,Witte N, Duppen D, Stuck AE, Kempen GI, et al. Limitations in activities of daily living in community-dwelling people aged 75 and over: A systematic literature review of risk and protective factors. PLoS One. 2016;11(10):e0165127.

11. Díaz-Venegas C, Reistetter TA, Wang CY, Wong R. The progression of disability among older adults in Mexico. Disabil Rehabil. 2016;38(20):2016- 2027.

12. Júnior JSV, Tribess S, Rocha SV, Sasaki JE, Garcia CA, Meneguci J, et al. Sedentary behavior as a predictor of functional disability in older adults. Rev Bras Ativ Fís Saúde 2018;23:1-7.

13. Matthews CE, Chen KY, Freedson PS, Buchowski MS, Beech BM, Pate RR, et al. Amount of time spent in sedentary behaviors in the United States, 2003-2004. Am J Epidemiol. 2008;167(7):875-881.

14. Dogra S, Ashe MC, Biddle SJH, Brown WJ, Buman MP, Chastin $\mathrm{S}$, et al. Sedentary time in older men and women: An international consensus statement and research priorities. Br J Sports Med. 2017;51(21):1526-1532.
15. Hallal PC, Andersen LB, Bull FC, Guthold R, Haskell W, Ekelund U. Global physical activity levels: Surveillance progress, pitfalls, and prospects. The Lancet. 2012;380(9838):247-257.

16. Pate RR, O'Neill JR, Lobelo F. The evolving definition of "sedentary". Exerc Sport Sci Rev 2008;36(4):173-178.

17. Matthews CE, Chen KY, Freedson PS, Buchowski MS, Beech BM, Pate RR, et al. Amount of time spent in sedentary behaviors in the United States, 2003-2004. Am J Epidemiol. 2008; 167(7):875-881.

18. Sun F, Norman IJ, While AE. Physical activity in older people: a systematic review. BMC Public Health. 2013; 13:449.

19. Lin SF, Beck AN, Finch BK, Hummer RA, Masters RK. Trends in US older adult disability: exploring age, period, and cohort effects. Am J Public Health. 2012; 102(11):2157-2163.

20. Rosenberg DE, Bellettiere J, Gardiner PA, Villarreal VN, Crist K, Kerr J. Independent associations between sedentary behaviors and mental, cognitive, physical, and functional health among older adults in reti

21. Dunlop DD, Song J, Arntson EK, Semanik PA, Lee J, Chang RW, et al. Sedentary time in US older adults associated with disability in activities of daily living independent of physical activity. J Phys Act Health. 2015;12(1):93-101.

22. León-Muñoz LM, Martínez-Gómez D, Balboa-Castillo T, López-García E, Guallar-Castillón P, Rodríguez-Artalejo F. Continued sedentariness, change in sitting time, and mortality in older adults. Med Sci Sports Exerc. 2013;45(8):1501-1507.

23. Koolhaas CM, Dhana K, Van Rooij FJA, Kocevska D, Hofman A, Franco $\mathrm{OH}$, et al. Sedentary time assessed by actigraphy and mortality: The Rotterdam Study. Prev Med. 2017;95:59-65.

24. DiPietro L, Jin Y, Talegawkar S, Matthews CE.The Joint Associations of Sedentary Time and Physical Activity With Mobility Disability in Older People: The NIH-AARP Diet and Health Study. J Gerontol A Biol Sci Med Sci. 2018;73(4):532-538.

25. Dogra S, Ashe MC, Biddle SJH, Brown WJ, Buman MP, Chastin S, et al. Sedentary time in older men and women: an international consensus statement and research priorities. Br J Sports Med.2017;51(21):15261532.

26. García-Esquinas E, Andrade E, Martínez-Gómez D, Caballero FF, López-García E, Rodríguez-Artalejo F. Television viewing time as a risk factor for frailty and functional limitations in older adults: Results from 2 European prospective cohorts. Int J Behav Nutr Phys Act. 2017;14: 54 .

27. Liberati A, Altman DG, Tetzlaff J, Mulrow C, Gøtzsche PC, Ioannidis JP, et al. The PRISMA statement for reporting systematic reviews and meta- analyses of studies that evaluate healthcare interventions: explanation and elaboration.BMJ. 2009;339:b2700.

28. Borenstein M, Hedges LVL, Higgins JJPT, Rothstein HHR. FixedEffect versus Random-Effects Models. Introduction to Meta-Analysis (1st edn), A John Wiley \& Songs, Ltd, West sussex,England, UK, 2009; Pp. 77-85.

29. Hunter JE, Schmidt F. Meta Analysis of Correlations Corrected Individually for Artifacts. In: Cuevas-Shaw L, Crouppen M, Foster SD (eds) Methods of Meta-Analysis Correcting Error and Bias in Reseach Findings (2nd edn), SAGE publications, Inc. 24 Tellar Road, Thousand Oaks, California 91320,USA, 1939; Pp. 81-90.

30. $\mathrm{R}$ Core Team. R: A language and environment for statistical computing. R Foundation for Statistical Computing, Vienna, Austria. 2013. https://www.r- project.org/

31. Elm EV, Altman DG, Egger M, Pocock SJ, Gøtzsche PC, Vandenbroucke JP. The strengthening the reporting of observational studies in epidemiology (STROBE) statement: Guidelines for reporting observational studies. J Clin Epidemiol. 2008;61(4):344-349. 
32. Manns P, Ezeugwu V, Armijo-Olivo S, VallanceJ, Healy GN. Accelerometerderived pattern of sedentary and physical activity time in persons with mobility disability: National Health and Nutrition Examination Survey 2003 to 2006. J Am Geriatr Soc. 2015;63(7):1314-1323.

33. Marques EA, Baptista F, Santos DA, Silva AM, Mota J, Sardinha LB. Risk for losing physical independence in older adults: The role of sedentary time, light, and moderate to vigorous physical activity. Maturitas.2014;79(1):91-95.

34. Yen CH, Ku MH, Wang CY. Self-reported Sitting Time is Associated with Decreased Mobility in Older Adults. J Geriatr Phys Ther. 2017;40(3):167-173.

35. Mataratzis PSR, Accioly E, Padilha PC. Micronutrient deficiency in children and adolescents with sickle cell anemia: a systematic review. Rev bras hematol hemoter. 2010;32(3):247-256.

36. Ku PW, Liu Y Te, Lo MK, Chen LJ, Stubbs B. Higher levels of objectively measured sedentary behavior is associated with worse cognitive ability: Two- year follow-up study in community-dwelling older adults. Exp Gerontol. 2017 ;99:110-114.

37. Vaz Fragoso CA, Miller ME, Fielding RA, King AC, Kritchevsky $\mathrm{SB}, \mathrm{McDermott} \mathrm{MM}$, et al. Sleep-wake disturbances in sedentary community-dwelling elderly adults with functional limitations. J Am Geriatr Soc.2014;62(6):1064-1072.

38. Martínez-Gómez D, Guallar-Castillón P, León-Muñoz LM, RodríguezArtalejo F. Household physical activity and mortality in older adults: A national cohort study in Spain. Prev Med Elsevier. 2014;61:14-19.

39. Jefferis BJ, Merom D, Sartini C, Wannamethee SG, Ash S, Lennon LT, et al. Physical activity and falls in older men: The critical role of mobility limitations. Med Sci Sports Exerc. 2015; 47(10): 2119-2128.

40. Banks E, Jorm L, Rogers K, Clements M, Bauman A. Screen-time, obesity, ageing and disability: Findings from 91266 participants in the 45 and Up Study. Public Health Nutr. 2011;14(1):34-43.

41. Espinel PT, Chau JY, Van der Ploeg HP, Merom D. Older adults' time in sedentary, light and moderate intensity activities and correlates: Application of Australian Time Use Survey. J Sci Med Sport. 2015;18(2):161-166.

42. Van der Ploeg HP, Chey T, Ding D, Chau JY, Stamatakis E, Bauman AE. Standing time and all-cause mortality in a large cohort of Australian adults. Prev Med.2014;69(1):187-191.
43. Coqueiro RDS, de Queiroz BM, Oliveira DS, das Merces MC, Oliveira Carneiro JA, Pereira R, et al. Cross-sectional relationships between sedentary behavior and frailty in older adults. J Sports Med Phys Fitness. 2017;57(6):825-830

44. Kim J, Im JS, Choi YH. Objectively measured sedentary behavior and moderate-to-vigorous physical activity on the health-related quality of life in US adults: The National Health and Nutrition Examination Survey 2003-2006. Qual Life Res. 2017;26(5):1315-1326.

45. Guallar-Castillón P, Sagardui-Villamor J, Banegas JR, Graciani A, Fornés NS, García EL, et al. Waist circumference as a predictor of disability among older adults. Obesity. 2007;15(1):233-244.

46. Meneguci J, Sasaki JE, Da Silva Santos Á, Scatena LM, Damião R. Socio-demographic, clinical and health behavior correlates of sitting time in older adults. BMC Public Health. 2015;15:65.

47. Van Der Berg JD, Bosma H, Caserotti P, Eiriksdottir G, Arnardottir NY, Martin KR, et al. Midlife determinants associated with sedentary behavior in old age. Med Sci Sports Exerc. 2014;46(7):1359-1365.

48. VanCauwenberg J, De Donder L, Clarys P, De Bourdeaudhuij I, Owen N, Dury S, et al. Relationships of individual, social, and physical environmental factors with older adults' television viewing time. J Aging Phys Act. 2014;22(4):508-517.

49. Chen T, Narazaki K, Haeuchi Y, Chen S, Honda T, Kumagai S. Associations of Sedentary Time and Breaks in Sedentary Time with Disability in Instrumental Activities of Daily Living in CommunityDwelling Older Adults. J Phys Act Health. 2016;13(3):303-309.

50. Copeland JL, Ashe MC, Biddle SJ, Brown WJ, Buman MP, Chastin S, et al. Sedentary time in older adults: A critical review of measurement, associations with health, and interventions. $\mathrm{Br} \mathrm{J}$ Sports Med. 2017;51(21):1539.

51. Gardiner PA, Reid N, Gebel K, Ding D. Sitting time and physical function in Australian retirees: An analysis of bidirectional relationships. J Gerontol A Biol Sci Med Sci. 2018;73(12):1675-1681.

52. Malta DC, Stopa SR, Canuto R, Gomes NL, Mendes VL, Goulart BN, et al. Self-reported prevalence of disability in Brazil, according to the National Health Survey, 2013. Cien Saude Colet. 2016;21(10):3253-3264.

53. Tak E, Kuiper R, Chorus A, Hopman-Rock M. Prevention of onset and progression of basic ADL disability by physical activity in community dwelling older adults: A meta-analysis. Ageing Res Rev. 2013;12(1):329-338. 